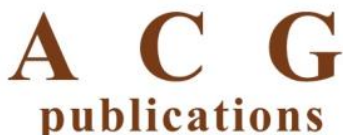

J. Chem. Metrol. 13:1 (2019) 1-6

journal of chemical metrology

\title{
High performance liquid chromatographic analysis of lercanidipine in human breast milk
}

\author{
Evrim Kepekçi Tekkeli $\odot^{1}$, Işıl Gazioğlu $\odot^{1^{*}}$, Gizem Tırıs $\odot^{1}$ and Cem Önal $\odot^{2}$ \\ ${ }^{I}$ Faculty of Pharmacy, Department of Analytical Chemistry, Bezmialem Vakif University, Fatih, \\ Istanbul, Türkiye \\ ${ }^{2}$ Abdi İbrahim Pharmaceuticals Hadimkoy/Istanbul, Türkiye
}

(Received March 20, 2019; Revised April 18, 2019; Accepted April 21, 2019)

\begin{abstract}
A simple, rapid, precise and accurate isocratic reversed phase HPLC method was developed and validated for the determination of lercanidipine hydrochloride in pharmaceutical tablets and spiked human breast milk. The chromatographic separation was achieved on $\mathrm{C} 18(250 \times 4.6 \mathrm{~mm} \times 5 \mu \mathrm{m})$ column using a mobile phase consisting of acetonitrile and phospate buffer $(\mathrm{pH}=4)(55: 45, \mathrm{v} / \mathrm{v})$ at a flow rate of $1.1 \mathrm{~mL} / \mathrm{min}$ and UV detection at $237 \mathrm{~nm}$. The linearity of the proposed method was investigated in the range of $1.0-40 \mu \mathrm{g} / \mathrm{mL}\left(\mathrm{r}^{2}=0.9990\right)$. The method was validated in terms of accuracy, precision, reproducibility, specificity, robustness, and detection and quantification limits, in accordance with ICH guidelines. The proposed method is found as suitable for routine quantification of lercanidipine in human breast milk.
\end{abstract}

Keywords: Antihypertensive; lercanidipine hydrochloride; HPLC-UV; human breast milk; method validation $@$ 2019 ACG Publications. All rights reserved.

\section{Introduction}

Lercanidipine (LER), ( \pm )2-[(3,3-diphenylpropyl) methylamino]-1,1dimethylethyl methyl (4RS)-2,6-dimethyl-4-(3-nitrophenyl)-1-4-dihydropyridine-3,5-dicarboxylate (Figure 1), is a thirdgeneration lipophilic and vaso-selective dihydropyridine calcium-channel blocker developed for an oral administration and is used in hypertension treatments to effectively and safely reduce high levels of blood pressure, with a low adverse effect [1-3]. Lercanidipine hydrochloride in pharmaceutical tablets and spiked human breast milk was used.

The drug is orally administered as its hydrochloride salt in dose of 10-20 mg daily. It is rapidly absorbed from gastrointestinal tract, widely distributed and undergoes an extensive first pass metabolism $[4,5]$, generating mainly inactive metabolites. LER exhibits a short plasma half-life (ranges from 2 to $5 \mathrm{~h}$ ) but the therapeutic action is increased about $24 \mathrm{~h}$ due to its high liposolubility [1-3]. So, the analysis of LER is important for therapeutic drug monitoring.

Several high performance liquid chromatographic method (HPLC) analysis of LER in biological fluids or pharmaceutical preparations which involved HPLC-Ultraviole detection (HPLCUV) [6] HPLC-tandem mass spectrometry (MS/MS) [7-12], ultra-performance liquid chromatography

\footnotetext{
*Corresponding author: E-Mail: isilhacibekiroglu@gmail.com
} 
(UPLC)- MS/MS [13,14], high performance thin layer chromtagraphy (HPTLC) [15], voltammetry [16] and capillary electrophoresis [17] are used.

Human breast milk is the optimum source of nutrition during the first six months of life with several health and social benefits [18]. In our best knowledge and after an exhaustive revision of the literature there is no method about the determination of LER in human breast milk. Although breast milk is the most suitable nutrient for the infant, the breastfed child may be exposed to drugs during maternal drug therapy and for this reason it is important to determine the extent of medication that can be transferred to the milk, and how this may affect the development of the infant [19].<smiles>COC(=O)C1=C(C)NC(C)=C(C(=O)OC(C)(C)CN(C)CCC(c2ccccc2)c2ccccc2)C1c1cccc([N+](=O)[O-])c1</smiles>

Figure 1. Chemical structure of Lercanidipine

\section{Experimental}

In the present work, an HPLC method using UV detection was developed and validated according to ICH criteria [20] in order to determine LER in spiked human breast milk samples.

\subsection{Chemicals and Reagents}

LER was obtained from Shanghai Yingxuan Pharmaceutical Science \& Technology (China). Acetonitrile, monobasic dihydrogen phosphate and dibasic monohydrogen phosphate, hydrochloric acid (HPLC grade) and hexane (analytical grade) were supplied from Merck (Darmstadt, Germany). Water was purified by Human (Japan) ultrawater purification system.

\subsection{Solutions}

A stock solution of LER $(0.1 \mathrm{mg} / \mathrm{mL})$ was prepared and diluted with water to give standard solutions of from 1.0 to $40 \mu \mathrm{g} / \mathrm{mL}$.

Phosphate buffer was prepared by $2.0209 \mathrm{~g}$ of sodium phosphate dibasic and $0.3394 \mathrm{~g}$ of sodium phosphate monobasic solution in $50 \mathrm{~mL}$ water. The $\mathrm{pH}$ level was adjusted to 4 with $0.1 \mathrm{M}$ hydrochloric acid solution, and the volume was made up to $100 \mathrm{~mL}$ with water.

\subsection{Sample Preparation}

Breast milk samples were collected from a 35 years old volunteer mother (informed consent form was obtained according to ethical commitee approval) into polyethylene storage packs. The milk samples were stored at $-20^{\circ} \mathrm{C}$. To extract the drug from the milk samples different extraction techniques such as liquid-liquid extraction (LLE) with various extraction solvents and solid phase extraction (SPE) with various cartridge type and lengths were trialed.

\subsection{Instrumentation}

Spectrophotometric measurements were carried out using a Shimadzu UV-160 A spectrophotometer with $1 \mathrm{~cm}$ glass cells to obtain the spectrum of LER. 
The HPLC analyses were conducted on a Shimadzu (Japan) LC 20 liquid chromatography which includes a LC-20AT pump, SIL AT-HT autosampler part, a SPD-20A HT UV spectrophotometric detector and CTO 10 AC column oven. Different mobile phase and column type and size combinations were trialed with different flow rates and column temperatures in order to get the most efficient chromatographic separation.

\subsection{Data Evalaution and Discussion}

\subsubsection{Sample preparation Process}

For the extraction of the lercanidipine from the human breast milk, $2 \mathrm{~mL}$ milk was alkalinized with $250 \mu \mathrm{L} 0.1 \mathrm{M} \mathrm{NaOH}$, and the solution was then extracted into $5 \mathrm{~mL}$ of hexane. The contents were mixed with vortex mixer at moderate speed for $5 \mathrm{~min}$ and centrifuged at $4500 \times \mathrm{g}$ for $3 \mathrm{~min}$. The aqueous layer was discarded. The organic layer was evaporated to dryness under nitrogen at room temperature. The residue was dissolved in $300 \mu \mathrm{L}$ acetonitrile. The solution was mixed with a vortex mixer for $30 \mathrm{sec}$. and $20 \mu \mathrm{L}$ sample was injected into the HPLC-UV system.

\subsubsection{Chromatographic Process}

Maximum absorption of LER was observed at $237 \mathrm{~nm}$ by UV spectrophotometer and chromatographic separation was performed by isocratic elution at room temperature on a GL Sciences (Japan) C18 (ODS) column with acetonitrile and phosphate buffer $(\mathrm{pH}=4)(55: 45, \mathrm{v} / \mathrm{v})$ with a flow rate of $1.1 \mathrm{~mL} / \mathrm{min}$ The chromatograms of standard LER solution and blank solution and breast milk sample solution including LER are given in Figure 2, Figure S1 and Figure S2.

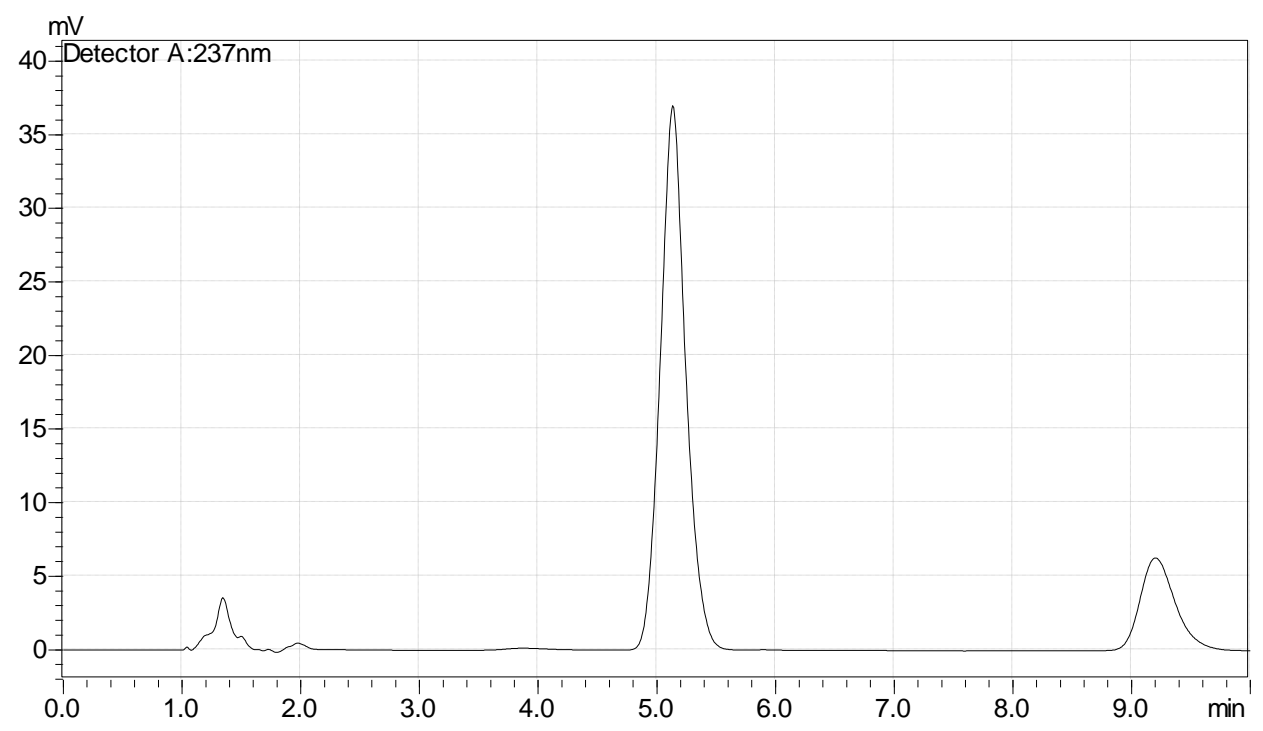

Figure 2. $10 \mu \mathrm{g} / \mathrm{mL}$ of LER

\section{Results and Discussion}

\subsection{Validation of the Method}

Validation of the method was applied according to the following guidelines given by the International Conference on Harmonization (ICH) (11). 


\subsubsection{Linearity}

Calibration curve was prepared by the analysis of standard solutions of LER with various concentrations between 1.0-40 $\mu \mathrm{g} / \mathrm{mL}$. According to linear least-squares regression analysis, the linear concentration ranges (each concentration was studied as five replicates) of the method was determined and the equation of the calibration curve was calculated as $\mathrm{y}=49981 \mathrm{x}+7000,5$, where $y$ shows the peak areas and $x$ indicates the concentrations of LER in $1.0-40 \mu \mathrm{g} / \mathrm{mL}$.

\subsubsection{The limit of Detection (LOD) and Limit of Quantitation ( $L O Q)$}

LOD and LOQ were determined using the formula: $\mathrm{LOD}$ or $\mathrm{LOQ}=\mathrm{kSDa} / \mathrm{b}$, where $\mathrm{k}=3.3$ for LOD and 10 for LOQ, SDa is the standard deviation of the intercept, and b is the slope. The parameters for the analytical performance of the proposed method are summarized in Table 1.

Table 1. The analytical parameters of the method

\begin{tabular}{ll}
\hline Parameters & Method \\
\hline Concentration range $^{\mathrm{a}}(\mu \mathrm{g} / \mathrm{mL})$ & $1-40$ \\
Regression equation $^{\mathrm{b}}$ & $\mathrm{y}=49981 \mathrm{x}+7000.5$ \\
Intercept $\pm \mathrm{SD}^{\mathrm{S}}$ & $7005 \pm 21.44$ \\
Slope $\pm \mathrm{SD}$ & $49981 \pm 67.53$ \\
Correlation coefficient $\left(\mathrm{r}^{2}\right)$ & 0.9990 \\
$\mathrm{LOD}(\mu \mathrm{g} / \mathrm{mL})$ & 0.33 \\
$\mathrm{LOQ}(\mu \mathrm{g} / \mathrm{mL})$ & 1 \\
\hline${ }^{\mathrm{a}} \mathrm{Average}$ of five determinations & \\
${ }^{\mathrm{b}} \mathrm{y}=\mathrm{xC}+\mathrm{b}$ where $\mathrm{C}$ is the concentration in $\mu \mathrm{g} / \mathrm{mL}$ and $\mathrm{y}$ is the peak area
\end{tabular}

\subsubsection{Accuracy, Precision and Recovery}

QC samples at three different concentrations $(3,15.0$, and $35.0 \mu \mathrm{g} / \mathrm{mL})$ that can be selected as low, medium and high concentrations $(\mathrm{n}=5)$ in milk and aqueous sample were prepared. The accuracy was determined by recovery values and the precision of the recovery study were defined by RSD values of the recovery results in five replicate studies. The recovery of LER from human breast milk was examined by extraction of spiked milk samples and comparison with peak areas obtained from the same amounts of aqueous unextracted LER solutions. The mean absolute recovery of LER were of $97.3 \%$. Five replicates of samples at each concentration were studied on the same day for intraday and on five different days for interday precision and accuracy. The RSD values of both intraday and interday assays were all less than $4.13 \%$. According to all these results summarized in Table 2 good precision and accuracy were observed.

Table 2. Accuracy and precision of the method

\begin{tabular}{llllll}
\hline $\begin{array}{l}\text { Added } \\
\text { concentration } \\
(\mu \mathrm{g} / \mathrm{mL})\end{array}$ & $\begin{array}{l}\text { Found } \\
\text { concentration } \\
(\mu \mathrm{g} / \mathrm{mL})\end{array}$ & $\begin{array}{l}\text { Recovery } \\
(\%)\end{array}$ & $\begin{array}{l}\text { RSD of } \\
\text { recovery }\end{array}$ & $\begin{array}{l}\text { RSD of } \\
\text { intraday } \\
\text { variation }\end{array}$ & $\begin{array}{l}\text { RSD of } \\
\text { interday } \\
\text { variation }\end{array}$ \\
& $\left(\mathrm{Mean} \pm \mathrm{SD}^{1}\right)$ & & & &
\end{tabular}

\begin{tabular}{llllll}
\hline 3.00 & $2.94 \pm 0.06$ & 98.0 & 2.57 & 2.26 & 3.15 \\
15.00 & $14.63 \pm 0.82$ & 97.5 & 3.18 & 3.75 & 4.13 \\
35.00 & $33.79 \pm 2.12$ & 96.5 & 3.45 & 2.67 & 3.92 \\
& & & & &
\end{tabular}

For each concentration $(n=5)$ 


\subsubsection{Robustness}

Robustness was assessed by determination of the QC samples at three concentration levels as described at validation section above $(n=3)$. The parameters, that are changed to measure the robustness of the method, are flow-rate, column oven temperature, acetonitrile and aqueous phase contents of the mobile phase. The mobile phase proportions were changed from 55:45 (acetonitrilebuffer solution) to 50:50 and 60:40 and the flow rate was changed from 1.1 to 0.8 and $1.4 \mathrm{~mL} / \mathrm{min}$. These changes had no significant effect on peak area and resolution.

\subsubsection{Stability}

The effects of freezing and thawing on LER concentrations were studied using spiked LER milk standards at $3,15,35 \mu \mathrm{g} / \mathrm{mL}$, which were subjected to four freeze-thaw cycles before analysis. The stability of LER in spiked milk stored at room temperature for $24 \mathrm{~h}$ and $-20^{\circ} \mathrm{C}$ for 2 weeks was evaluated, as well. Stock solutions of LER were stable at least for 30 days when stored at $-20^{\circ} \mathrm{C}$. After 20 days no decrease was observed in the concentration of LER in milk.

\section{Conclusion}

As a conclusion, this new method will fulfill the requirements for quantitation of LER in human breast milk. There is no method published for the determination of LER in this matrix. And the amount of LER is important in order to understand the effects of this drug on infants during breast feeding. In some situations mothers have to use different types of drugs during breast feeding. LER is a widely used vaso-selective dihydropyridine calcium-channel blocker that is preffered in hypertension theraphy. Its lipophilic structure may cause different accumulations in body and excretion by breast milk is possible. But there is no available data about this potential. This study will provide to quantify LER in human breast milk with a simple and cost reduced method. The sample pretreatment procedure depends on just one step LLE and immediately after HPLC with UV dedection provides sensitive analysis of LER. Preparation of the mobile phase is simple and nontoxic, no gradient elution is needed. Nearly in 5 min. selective and sensitive assay of LER can be carried out.

\section{Supporting Information}

Supporting information accompanies this paper on http://www.acgpubs.org/journal/journal-ofchemical-metrology

\section{ORCID}

Evrim Kepekçi Tekkeli: 0000-0002-1871-017X

Iș1l Gazioğlu: 0000-0002-3283-1824

Gizem Tiris: 0000-0002-2547-6086

Cem Önal: 0000-0002-5840-7386

\section{References}

[1] K. J. McClellan and B. Jarvis (2000). Lercanidipine - A review of its use in hypertension, Drugs 60, 1123-1140.

[2] L. M. Bang, T. M. Chapman and K. L. Goa (2003). Lercanidipine - A review of its efficacy in the management of hypertension, Drugs 63, 2449-2472.

[3] M. Burnier, M. Pruijm and G. Wuerzner (2009). Treatment of essential hypertension with calcium channel blockers: what is the place of lercanidipine? Expert Opin. Drug Metab. Toxicol. 5, 981-987. 
[4] L. G. Herbette, M. Vecchiarelli, A. Sartani andA. Leonardi (1998). Lercanidipine: short plasma halflife, long duration of action and high cholesterol tolerance. Updated molecular model to rationalize its pharmacokinetic properties, Blood Press. Suppl. 2, 10-17.

[5] V. B. Boralli, E. B. Coelho, S. A. Sampaio, M. P. Marques and V. L. Lanchote (2009). Enantioselectivity in the pharmacokinetic interaction between fluvastatin and lercanidipine in healthy volunteers, J. Clin. Pharmacol. 49, 205-211.

[6] G. Coppi and M. Barchielli (1991). Simple High-Performance Liquid-Chromatographic Method for the Determination of Pgt/1a, a New Immunostimulating Drug, in Biological-Fluids, J. Chromatogr-Biomed. 563, 385-391.

[7] I. I. Salem, J. Idrees, J. I. Al Tamimi and P. Farina (2004). Selective and rapid liquid chromatographymass spectrometry method for the determination of lercanidipine in human plasma, J. Chromatogr. B. 803, 201-207.

[9] E.M. B. Sabi-mouka, J. E. Agbokponto, E. Zhang, Q. Li and L. Ding (2016). Simultaneous determination of a fixed-dose combination of lercanidipine and valsartan in human plasma by LC-MS-MS: Application to a pharmacokinetic study, J. Chrom. Sci. 54, 1553-1559.

[10] A. B. Baranda, C. A. Mueller, R. M. Alonso, R. M. Jimenez and W. Weinmann (2005). Quantitative determination of the calcium channel antagonists amlodipine, lercanidipine, nitrendipine, felodipine, and lacidipine in human plasma using liquid chromatography-tandem mass spectrometry, Ther Drug Monit. 27, 44-52.

[11] K. Chen, J. Zhang, S. Liu, D. Zhang, Y. Teng, C. Wei, B. Wang, X. Liu, G. Yuan, R. Zhang, W. Zhao and R. Guo (2012). Simultaneous determination of lercanidipine, benazepril and benazeprilat in plasma by LC-MS/MS and its application to a toxicokinetics study, J. Chromatogr. B, 899, 1-7.

[12] X. Li, F. Shi and X. He (2016). A rapid and sensitive LC-MS/MS method for determination of lercanidipine in human plasma and its application in a bioequivalence study in Chinese healthy volunteers, J. Pharm. Biomed. Anal. 128, 67-72.

[13] M. Kalovidouris, S. Michalea, N. Robola, M. Koutsopoulou and I. Panderi (2006). Ultra-performance liquid chromatography/tandem mass spectrometry method for the determination of lercanidipine in human plasma, Rapid Commun. Mass. Sp. 20, 2939-2946.

[14] D. V. Chaudhary, D. P. Patel and P. A. Shah (2016). New improved UPLC-MS-MS method for reliable determination of clarithromycin in human plasma, J. Pharm. Anal. 6, 87-94.

[15] S. B. Wankhede and S. M. Philip (2016). Sensitive high performance thin layer chromatographic determination of lercanidipine hydrochloride in pharmaceuticals and in blood plasma, Eur. J. Anal. Chem. 11, 141-154.

[16] F. Ozturk, D. Zeybek and E. Koyuncu Kilic (2014). Voltammetric behavior of lercanidipine and anodic adsorptive stripping voltammetric method for assay in pharmaceutical dosage forms and biological fluids, Bulg. Chem. Commun. 46, 764-770.

[17] L. P. Lourenco, F. A. Aguiar and A. R. Moraes de Oliveira (2015). Quantitative determination of lercanidipine enantiomers in commercial formulations by capillary electrophoresis, J. Anal. Methods In Chem.1-9

[18] J. Raisler, C. Alexander and P. O'Campo (1999). Breast-feeding and infant illness: A dose-response relationship? Am. J. Public Health, 89, 25-30

[19] B. Friguls, X. Joya, O. Garcia-Algar, C. R. Pallas, O. Vall, S. Pichini (2010). A comprehensive review of assay methods to determine drugs in breast milk and the safety of breastfeeding when taking drugs, Anal. Bioanal. Chem. 397, 1157-1179.

[20] Text on validation of analytical procedures Q2A, (2005), Geneva.

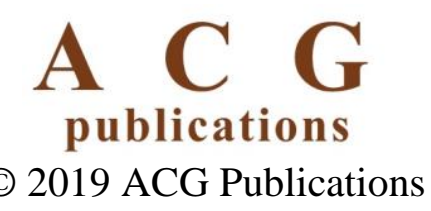

